\title{
Effect of Snow Grain Shape on Snow Albedo ${ }^{\mathfrak{O}}$
}

\author{
Cheng DANG, QIANG Fu, AND STEPHEN G. WARREN \\ Department of Atmospheric Sciences, University of Washington, Seattle, Washington
}

(Manuscript received 14 September 2015, in final form 8 June 2016)

\begin{abstract}
Radiative transfer models of snow albedo have usually assumed a spherical shape for the snow grains, using Mie theory to compute single-scattering properties. The scattering by more realistic nonspherical snow grains is less in the forward direction and more to the sides, resulting in a smaller asymmetry factor $g$ (the mean cosine of the scattering angle). Compared to a snowpack of spherical grains with the same area-to-mass ratio, a snowpack of nonspherical grains will have a higher albedo, thin snowpacks of nonspherical grains will more effectively hide the underlying surface, and light-absorbing particles in the snowpack will be exposed to less sunlight. These effects are examined here for nonspherical snow grains with aspect ratios from 0.1 to 10 . The albedo of an opaque snowpack with equidimensional (i.e., aspect ratio 1) nonspherical snow grains is higher than that with spherical snow grains by 0.032 and 0.050 , for effective grain radii of 100 and $1000 \mu \mathrm{m}$, respectively. For an effective radius of $100 \mu \mathrm{m}$, the albedo reduction caused by $100 \mathrm{ng} \mathrm{g}^{-1}$ of black carbon is 0.019 for spherical snow grains but only 0.012 for equidimensional nonspherical snow grains. The albedo of a snowpack consisting of nonspherical snow grains can be mimicked by using a smaller grain of spherical shape; this is why radiative transfer models using spherical grains were able to match measurements of spectral albedo. The scaling factor for snow grain radius is different for nonspherical grains with different aspect ratios and is about 2.4 for equidimensional snow grains.
\end{abstract}

\section{Introduction}

The albedo of snow is higher than that of any other natural surface on Earth, but it varies greatly with wavelength, snow condition, and the amount of lightabsorbing particles (LAPs) in snow (Wiscombe and Warren 1980; Warren and Wiscombe 1980; Warren 1982; Aoki et al. 2000; Carmagnola et al. 2013). A change of snow albedo directly affects the solar energy absorbed by a snowpack, influencing climate (Hansen and Nazarenko 2004; Flanner et al. 2007; Bond et al. 2013), hydrology through determining the melting rate (Painter et al. 2007, 2012; Qian et al. 2009), and snow photochemistry (Grannas et al. 2007; Zatko et al. 2013). Therefore, an

Supplemental information related to this paper is available at the Journals Online website: http://dx.doi.org/10.1175/ JAS-D-15-0276.s1.

Corresponding author address: Cheng Dang, Department of Atmospheric Sciences, University of Washington, 408 Atmospheric Sciences-Geophysics (ATG) Building, Box 351640, Seattle, WA 98195.

E-mail: chengd1@atmos.washington.edu accurate calculation of snow albedo is crucial for modeling environmental processes involving snow.

In current climate and hydrology models, snow albedo is calculated using either a coupled radiative transfer model or a parameterization developed based on radiative transfer calculations. Models calculating the spectral albedo of snow were developed in 1980 for pure snow by Wiscombe and Warren (1980) and for snow containing black carbon (BC) by Warren and Wiscombe (1980). Their work was adapted later by Flanner and his colleagues, who developed a multilayer radiative transfer model called the Snow, Ice, and Aerosol Radiative (SNICAR) model, which allows one to simulate snow albedo for different snow conditions and different contents of LAPs (Flanner et al. 2007, Flanner and Zender 2006). The SNICAR model has been incorporated as a subroutine in the standard implementation of National Center for Atmospheric Research's (NCAR's) Community Earth System Model (Lawrence et al. 2011). For climate studies with longer time scales, a parameterization of snow albedo for a few bands, instead of a spectral radiative transfer model, is more practical. Various parameterizations have been developed to calculate the broadband and narrowband albedo of snow 
(e.g., Marshall and Warren 1987; Gardner and Sharp 2010; Aoki et al. 2011; Dang et al. 2015). Those authors used radiative transfer models to calculate the snow albedo for different snow conditions and LAP contents and then fitted the snow albedo to analytical functions that can be used in climate models. These models and parameterizations have considered many factors that influence the snow albedo, including snow grain size, snow depth, solar zenith angle, underlying surface albedo, cloud optical thickness, and content of LAPs. However, they share one fundamental assumption-namely, that a snowpack can be represented by a collection of ice spheres. That assumption is questionable.

The shapes of snow grains (ice crystals) in nature vary significantly depending on the snow age and meteorological conditions during and after snowfall and are usually nonspherical and irregular in shape (LaChapelle 1969). To calculate the snow albedo using a radiative transfer model, one needs to know a priori the singlescattering properties of ice crystals: extinction efficiency, single-scattering albedo $\varpi$, and asymmetry factor $g$. Physically based methods (e.g., geometric optics, ray tracing, and Monte Carlo) to calculate these properties are available for various shapes of crystals (e.g., Yang and Liou 1995, 1996; Macke et al. 1996; Sun et al. 1999), but computationally efficient and well-established analytical methods are available only for spheres, by use of Mie theory (e.g., Wiscombe 1980). Resorting to Mie theory, it is therefore common practice to represent a nonspherical ice crystal by an effective spherical ice crystal with the same volume or the same surface area or a collection of effective spherical ice crystals with the same volume-to-area ratio (we adopt this definition when referring to effective snow grain radius in this paper). The effective radius $r_{e}$ is then defined by the specific surface area $\beta$ as

$$
r_{e} \equiv 3 / \rho_{i} \beta,
$$

where $\rho_{i}$ is the density of pure ice $\left(917 \mathrm{~kg} \mathrm{~m}^{-3}\right)$, and $\beta$ is the area-to-mass ratio of the bulk snowpack $\left(\mathrm{m}^{2} \mathrm{~kg}^{-1}\right)$. The accuracy of ice optical properties obtained by using such effective spheres is critical when performing the snow albedo calculation.

Beginning in the 1990s, a series of papers was published to evaluate the equal-volume-to-area representation for different shapes of ice crystals in clouds and snow, including circular cylinders (Grenfell and Warren 1999), hexagonal prisms (Fu et al. 1999; Neshyba et al. 2003), and hollow prisms (Grenfell et al. 2005). These studies show that the equal-volume-to-area prescription works well to compute the extinction efficiency and single-scattering albedo [as had also been shown in Fig. 1 of Fu et al. (1998)] but is less accurate for the asymmetry factor. The error in $g$ is largest if the aspect ratio of the nonspherical ice crystal is equal to 1 (equidimensional). For example, at wavelength $\lambda=0.5 \mu \mathrm{m}$, a sphere has $g=$ 0.89 but a solid equidimensional hexagonal prism has $g=0.77$ [Neshyba et al. (2003), their Fig. 7]. The calculated visible albedo of an ice cloud can therefore be quite inaccurate, despite the accurate extinction efficiency and single-scattering albedo.

Experimental evidence for how nonsphericity causes reduction of the asymmetry factor was shown in measurements on firn (old snow) and glacier ice in East Antarctica. In the case of ice, the scattering is by air bubbles in ice rather than ice grains in air, but the effects of nonsphericity may be similar. From measurements of spectral albedo, Dadic et al. (2013) inferred the specific surface area, which in the case of ice is the ratio of the area of bubbles and cracks to the mass of ice. This inference was made with a radiative transfer model using a spectral asymmetry factor $g$ for a spherical air bubble in ice, which is 0.86 at $\lambda=0.5 \mu \mathrm{m}$ (Mullen and Warren 1988). But the bubble shapes were not spherical, and direct measurements of $\beta$, obtained by x-ray tomography of the firn and ice samples, was $\sim 50 \%$ lower than the value inferred from the albedo measurement. Dadic et al. (2013) pointed out that, if they used the $\beta$ as obtained from measurement in the modeling, $g$ used in radiative transfer model needs to be reduced by factors ranging from 0.78 to 0.94 to match the measured albedo. For firn the average factor was 0.82 , implying $g \approx 0.71$. In other words, the measured $\beta$ and inferred $\beta$ could be brought into agreement if the radiative transfer model used $g \approx 0.71$ instead of $g=0.86$ at $\lambda=0.5 \mu \mathrm{m}$.

Experimental evidence also comes from measurements of ice crystals in clouds. The asymmetry factors of cirrus clouds derived from observation are 0.7 from Stephens et al. (1990), 0.75 from Garrett et al. (2001), and 0.8 from Francis et al. (1994). In the most recent MODIS retrieval algorithm (http://modis-atmos.gsfe. nasa.gov/products_C006update.html), a single habit of severely roughened aggregated columns with an asymmetry factor of 0.75 is assumed, which led to much improved agreement with the ice cloud optical depth retrieved from an independent method using the infrared channel (Holz et al. 2016). Therefore, both theory and observations, along with the knowledge that snow grains are nonspherical, indicate that the value of $g$ used to compute snow albedo is too large.

Many parameterizations of single-scattering properties of nonspherical ice crystals are available, aiming mainly for the application in retrieving and computing 
the optical properties of ice clouds (e.g., Fu 1996, 2007; Yang et al. 2000; Key et al. 2002; Baum et al. 2011; van Diedenhoven et al. 2014). Fewer have been developed for optical properties of nonspherical snow grains. Libois et al. $(2013,2014)$ studied the influence of snow grain shape on vertical profiles of solar irradiance and introduced two parameters (i.e., enhancement parameter and geometry asymmetry factor) to represent the snow grain shape. Very recently, Räisänen et al. (2015) developed a parameterization of the single-scattering properties of nonspherical snow grains based on the retrieved snow grain shape. The shape of snow grain they used is a combination of droxtals, plates, and Koch fractals, which they selected by matching the measured phase function of blowing snow. The calculated asymmetry factor of nonspherical grains using their parameterization is lower than that of spheres. Despite the complex shapes of snow grains, the asymmetry factor of a nonspherical ice crystal mainly depends on the aspect ratio and distortion of its constituent units, for which hexagonal prisms have been demonstrated to be valid optical proxies (Fu 2007; Yang and Fu 2009; van Diedenhoven et al. 2012). Retrievals obtained by applying this assumption to airborne polarimetric measurements of snow have been presented by Ottaviani et al. (2015).

A hexagonal prism is described by its aspect ratio (AR), the ratio of the diameter $2 a$ of the basal plane to the length $c(\mathrm{AR}=2 a / c)$. Snow crystals in the atmosphere often have very large or very small AR (plates or columns, respectively), but within a day or so after falling to the ground, processes of snow metamorphism (mainly by vapor transfer from convex to concave surfaces) cause the crystals to lose their intricate shapes and become more equidimensional (AR approaches 1) (LaChapelle 1969). Equidimensional nonspherical grains may appear similar to spheres, but their asymmetry factors actually show the greatest deviation from that of spherical grains. For a large range of $\mathrm{AR}(0.1<\mathrm{AR}<1), g$ of hexagonal prisms is smaller than $g$ of spheres with the same effective radius.

A smaller $g$ means that a photon is (on average) deflected through a larger angle in each scattering event, so it can reemerge from the top of the snowpack after fewer scattering events. This will cause the albedo of pure deep snow to be greater and will allow a thin snowpack to more effectively hide the underlying surface. As a consequence, a photon entering the snowpack is less likely to encounter LAPs (dust and BC) before reemerging. In this paper, we aim to make a comprehensive survey of the effects of the asymmetry factor on snow albedo calculations under various conditions for both pure snow and snow containing LAPs.

\section{Method}

\section{a. Single-scattering properties of ice and BC}

For spherical ice crystals, we calculated the extinction efficiency, single-scattering albedo, and asymmetry factor using Mie theory (Wiscombe 1980), with spectral optical constants of ice from Warren and Brandt (2008), for 29 grain radii $r$ from 20 to $2500 \mu \mathrm{m}$. For nonspherical ice crystals, we used the extinction efficiency and singlescattering albedo of spheres obtained from the Mie calculation and calculated their asymmetry factors using the parameterization developed by $\mathrm{Fu}$ (2007), assuming crystals with rough surfaces (light beams passing through the parallel planes of the ice crystals removed).

Fu (2007) parameterized the asymmetry factor of nonspherical ice crystals using the crystal mean aspect ratio and single-scattering albedo, for wavelength $\lambda$ ranging from 0.25 to $4 \mu \mathrm{m}$, and for ice crystals with both smooth and rough surfaces. We chose the parameterization for crystals with rough surfaces as it is more representative of ice crystals in natural snowpacks. Fu's parameterization was developed based on the asymmetry factor of hexagonal prisms, but it reproduced the asymmetry factor of other nonspherical ice crystals including bullet rosettes, aggregates with rough surfaces, and fractals, and its results agree with observations made by Garrett et al. (2001). Thus, in this work, we adopt Fu's parameterization to calculate the asymmetry factor of nonspherical ice crystals in general. The results obtained in this paper are expected to be applicable to a large variety of nonspherical crystal shapes.

The calculated $g$ of nonspherical ice crystals at wavelength $\lambda=0.5 \mu \mathrm{m}$ is shown in Fig. 1a. As was shown in Fig. 2a of Fu (2007), and similarly in Fig. 7 of Neshyba et al. (2003), the asymmetry factor of a nonspherical ice particle decreases as AR increases from 0.1 to 1 , then increases as AR increases from 1 to 10 , with minimum $g \approx 0.74$. For comparison, $g=0.89$ at $\lambda=0.5 \mu \mathrm{m}$ for a spherical ice crystal (Wiscombe and Warren 1980). Note that $g \approx 0.74$ is close to that suggested for firn based on observations (Dadic et al. 2013), as well as that used by the MODIS cloud optical depth retrieval (Holz et al. 2016), and that derived from in situ aircraft observations in ice clouds (Garrett et al. 2001).

The variation of $g$ with wavelength is shown in Fig. 1b for spherical ice crystals and for nonspherical ice crystals [data from $\mathrm{Fu}$ (1996), based on the geometric ray tracing given by Yang and Liou (1995)]. At visible wavelengths, the absorption of light by ice is so weak that the asymmetry factor is mainly determined by the shape of ice crystals, with little dependence on size. Spherical ice crystals with different effective radii have similar $g$, and $g$ of nonspherical ice crystals $(0.1<\mathrm{AR}<1)$ is much 

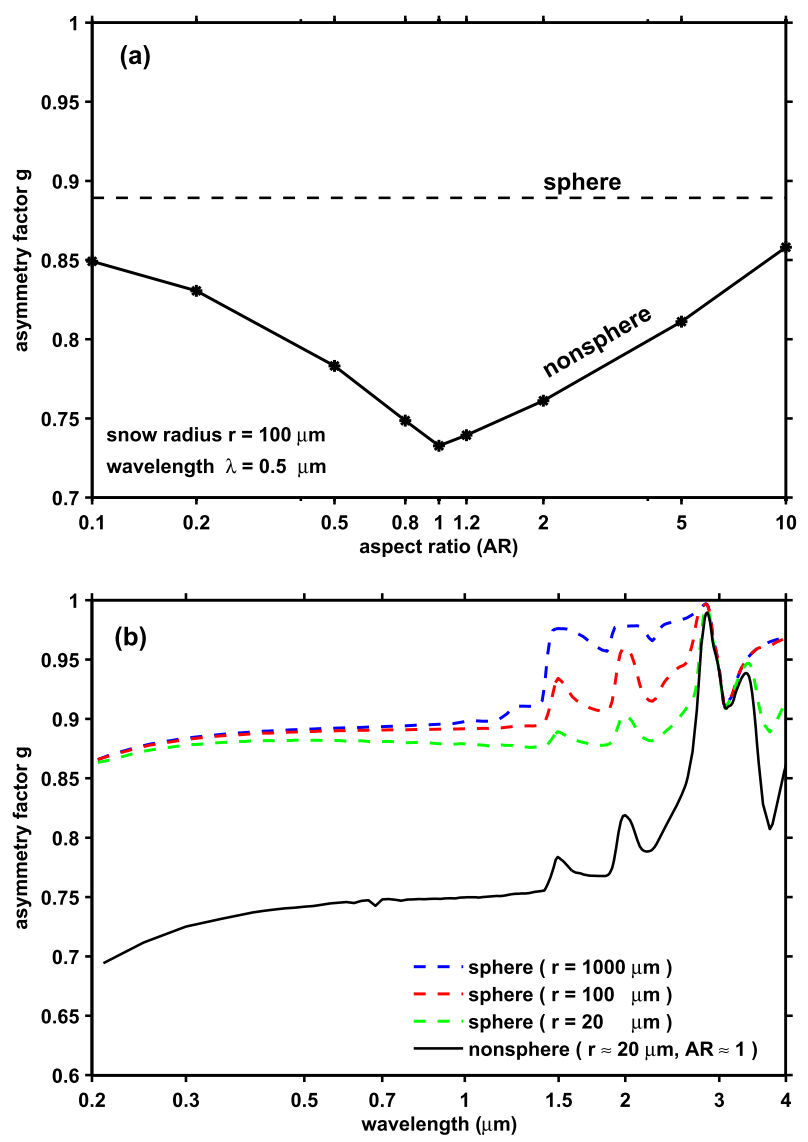

FIG. 1. (a) Asymmetry factor $g$ of a nonspherical ice crystal as a function of the aspect ratio (diameter/length) at wavelength $\lambda=0.5 \mu \mathrm{m}$. The values of $g$ are calculated using the parameterization given by $\mathrm{Fu}$ (2007) for ice crystals with rough surface. The asymmetry factor of a spherical ice crystal (dashed line; $g \approx 0.89$ ) is plotted as a reference. The effective radius of all ice crystals is $100 \mu \mathrm{m}$. (b) Asymmetry factor as a function of wavelength. The values of $g$ for spheres are computed using complex indices of refraction as given by Warren and Brandt (2008) for ice crystal radii $r=1000,100$, and $20 \mu \mathrm{m}$. The values of $g$ for nonspheres are given by $\mathrm{Fu}$ (1996) for ice with effective radius $r \approx 20 \mu \mathrm{m}$ and aspect ratio $\approx 1$ (Fu's ice crystal size spectra 5, with rough surface).

smaller than that of spherical ice crystals with the same area-to-mass ratio. For $\lambda>1.4 \mu \mathrm{m}$, the asymmetry factor depends on both particle shape and size. At these wavelengths, the absorption by ice becomes critical and a larger snow grain has a larger asymmetry factor. This is because the light intercepted by the larger grain is more likely to be absorbed, so the asymmetry factor is more dominated by the forward diffracted light [see Eq. (2.2) of Fu (2007)]. Within the very strong absorption band around $\lambda=3 \mu \mathrm{m}$, ice particles with different sizes and shapes all have $g \approx 1$. Since $80 \%$ of the solar energy is at $\lambda<1.4 \mu \mathrm{m}$ where ice is weakly absorptive, the big discrepancy of $g$ between spherical and nonspherical ice crystals is especially crucial in determining the albedo of a snowpack. Jin et al. (2008) show a similar dependence of the asymmetry factor on wavelength for grains with various shapes.

For BC, we use the same specifications as Dang et al. (2015). The density of $\mathrm{BC}$ is $1.8 \mathrm{~g} \mathrm{~cm}^{-3}$, with lognormal size distribution of geometric width 1.3 and mass mean diameter $0.13 \mu \mathrm{m}$ (Clarke et al. 1967). The complex refractive index of $\mathrm{BC}$ is $m=1.95-0.79 i$, independent of wavelength. We assume that the $\mathrm{BC}$ particles are spheres (so we use Mie theory to calculate their singlescattering properties) and that they are externally mixed with the ice crystals. The single-scattering properties of the mixture are therefore a combination of singlescattering properties of $\mathrm{BC}$ and ice crystals (Dang et al. 2015). The absorption will be enhanced if the $\mathrm{BC}$ is internally mixed with ice crystals (Flanner et al. 2012; Liou et al. 2014).

\section{b. Radiative transfer calculation}

Given single-scattering properties of snow, the spectral albedo of a snowpack is calculated using the deltaEddington approximation (Joseph et al. 1976; Wiscombe and Warren 1980). The spectral albedo is then used to calculate the broadband albedo $(\lambda=0.2-4 \mu \mathrm{m})$, using the incident solar spectrum measured at the sea surface in the Arctic Ocean during summer under clear sky by Grenfell and Perovich (2008). Considering a snow density of $300 \mathrm{~kg} \mathrm{~m}^{-3}$, we perform these calculations for snowpack of several thicknesses $(2,5,30,100$, and $99999 \mathrm{~cm}$; the latter, for this value of density, can be considered as "optically semi-infinite" for any grain size). We consider snow consisting of spherical snow grains and nonspherical snow grains of different AR, containing $\mathrm{BC}$ mass fractions varying from 0 (pure snow) to 1 (pure BC), and for four solar zenith angles (SZA): $0^{\circ}$, $30^{\circ}, 49.5^{\circ}$, and $75^{\circ}$. We assume the underlying ground is black (i.e., its albedo is 0 ).

Because the asymmetry factor of nonspherical ice crystals is roughly symmetric about $A R=1$ (Fig. 1a), we show the results only for $\mathrm{AR} \geq 1$. For $\mathrm{AR}<1$, the results are the same as the case of $\mathrm{AR}>1$ that has the same asymmetry factor. Moreover, we will show the results for $\mathrm{SZA}=49.5^{\circ}$ unless otherwise stated, since the cosine of this angle (0.65) is close to that of the insolation-weighted solar zenith cosine for the sunlit hemisphere of Earth.

\section{Results}

\section{a. Spectral albedo}

The spectral albedo $\alpha_{\lambda}$ of opaque deep snow is shown in Fig. 2 for both spherical grains and nonspherical grains with effective radii of 100 (new snow) and 

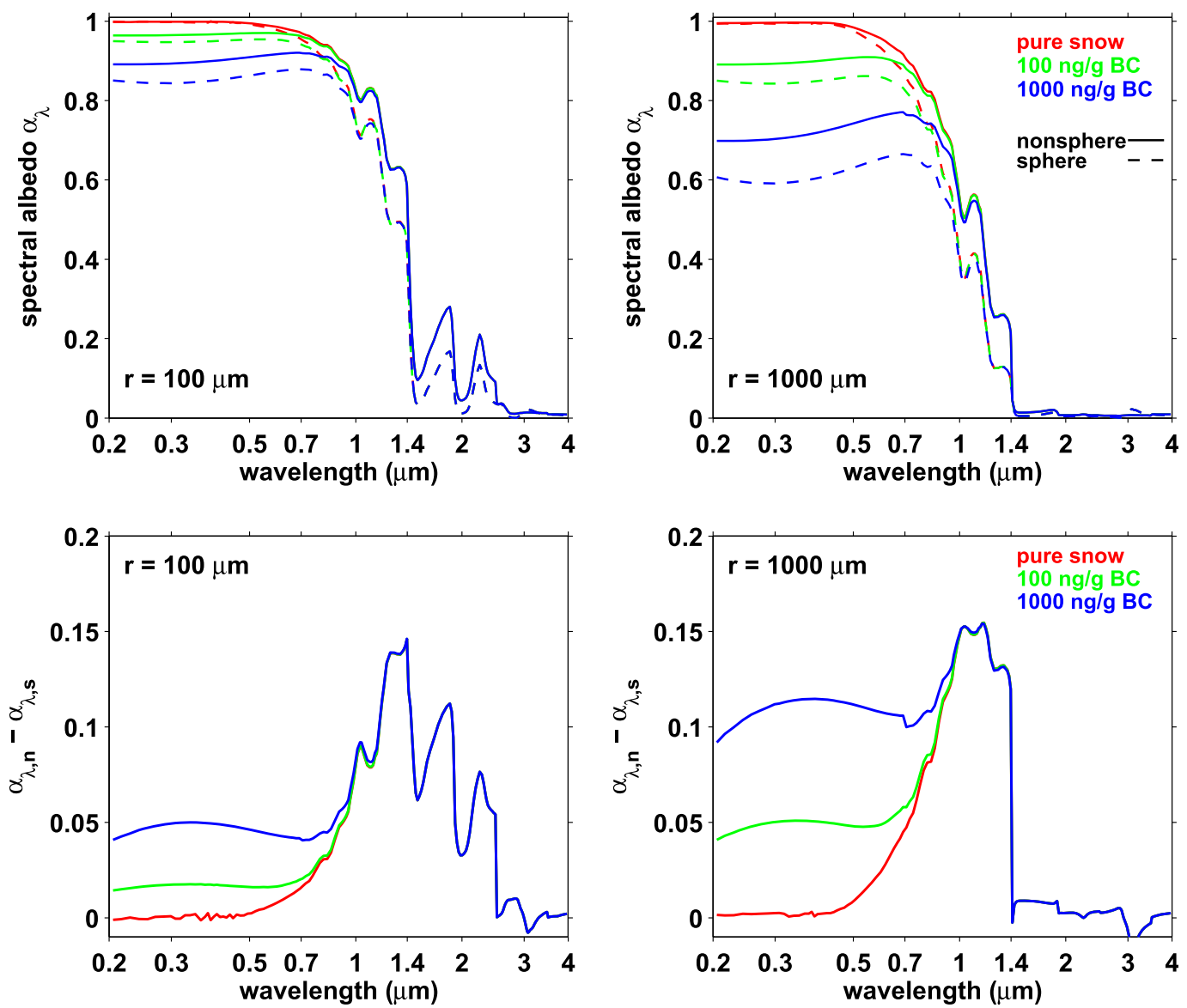

FIG. 2. (top) Spectral albedo $\alpha_{\lambda}$ of opaque snow consisting of spherical grains and nonspherical grains, for different BC contents, and for snow grain radii of 100 and $1000 \mu \mathrm{m}$. (bottom) Increase of spectral albedo if snow grains were nonspherical. The aspect ratio of the nonspherical snow grains is 1 . Here and in subsequent figures, subscripts $n$ and $s$ denote snow consisting of "nonspheres" and "spheres," respectively.

$1000 \mu \mathrm{m}$ (old snow). Recall from Fig. 1 that the asymmetry factor of nonspherical grains is smaller than that of spherical grains, so the light is less likely to be scattered forward and more likely to emerge out of the snowpack after fewer reflection and refraction events. If the absorption of light by opaque snow is very weak, the incident photons will eventually emerge out of the snowpack in both cases, so that at visible and ultraviolet wavelengths, the albedo of nonspherical snow and spherical snow are similar and close to 1 (top panel of Fig. 2). At near-IR wavelengths, where the snowpack is moderately absorptive, the photons traveling shorter distances in the snowpack are less likely to be absorbed; therefore, the albedo of nonspherical grains is larger than that of spherical grains.

The situation is different if the snow contains BC. For $\mathrm{BC}$ amounts up to $10^{4} \mathrm{ng} \mathrm{g}^{-1}$, higher $\mathrm{BC}$ concentration results in a larger albedo difference between nonspherical and spherical snow in the visible, while in the near IR, the albedo difference is almost independent of
$\mathrm{BC}$ concentration, since ice dominates the light absorption at these wavelengths (bottom panels of Fig. 2). After weighting the albedo difference by the incident solar spectrum, we find that for pure snow only $10 \%$ of the albedo difference is due to the visible band $(\lambda<$ $0.7 \mu \mathrm{m}$ ); as the $\mathrm{BC}$ concentration increases to 100 and $1000 \mathrm{ng} \mathrm{g}^{-1}$, this fraction increases to $25 \%$ and $55 \%$, respectively. The rest of the albedo difference is associated with the near-IR contribution. For shallow snow, the spectral albedo will also depend on the snow thickness and the albedo of the underlying surface, as will be shown later.

\section{b. Broadband albedo}

\section{1) DeEP SNOW}

For pure deep snow, the broadband albedo $\alpha$ of nonspherical grains is always larger than that of spherical grains (Fig. 3), as the asymmetry factor of nonspherical grains is smaller. The enhancement of snow 

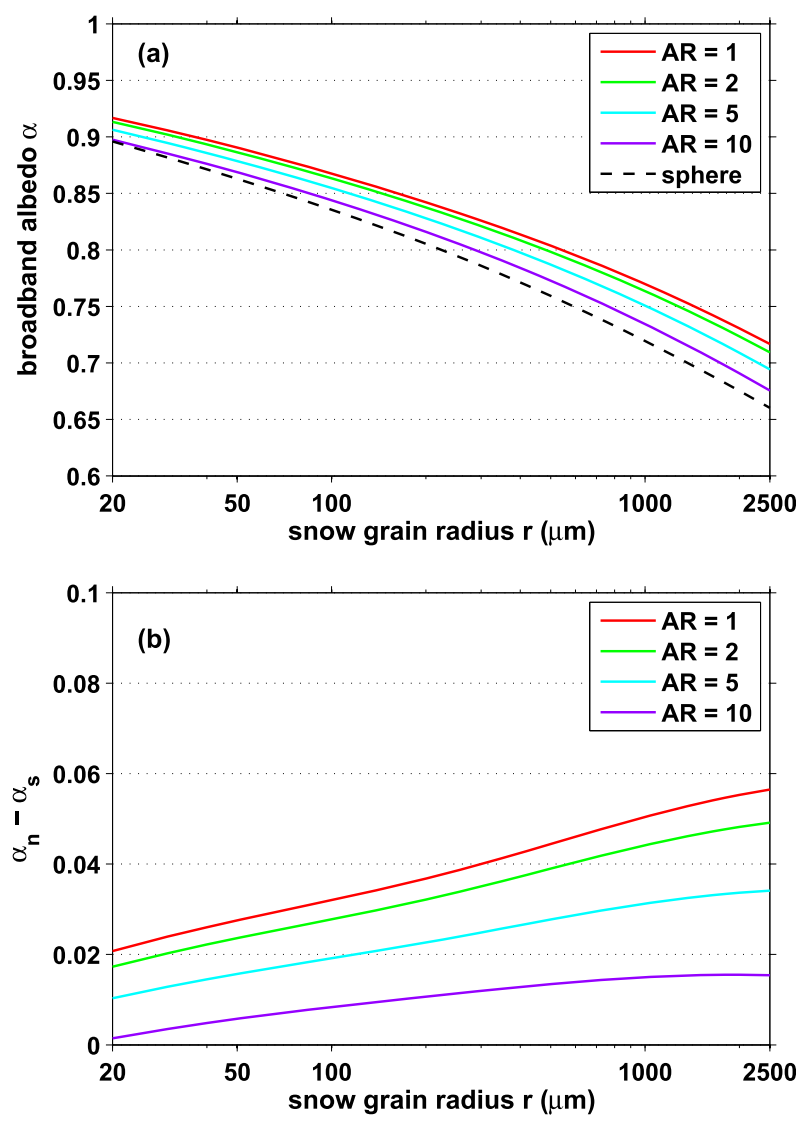

FIG. 3. (a) Broadband albedo $\alpha$ of pure snow as a function of snow grain radius. Solid curves show nonspherical ice crystals with aspect ratios $\mathrm{AR}=1,2,5$, and 10. The dashed curve is for a snowpack with spherical snow grains. (b) Increase of pure-snow albedo caused by nonsphericity.

albedo increases as the snow grain size increases: the coarse-grained snow is more sensitive to the change of asymmetry factor. For each grain size, an equidimensional nonspherical grain ( $\mathrm{AR}=1$, lowest asymmetry factor) shows the largest albedo increase. For snow with grain radii of 100 and $1000 \mu \mathrm{m}$, the albedo of equidimensional snow is higher by 0.032 and 0.050 , respectively.

For both nonspherical and spherical snow grains, the albedo reduction caused by adding $\mathrm{BC} \Delta \alpha$ is shown in Fig. 4. The reduction is smaller if the snowpack consists of nonspherical grains. For new snow $(r=100 \mu \mathrm{m})$ containing $100 \mathrm{ng} \mathrm{g}^{-1} \mathrm{BC}$, the albedo reduction is about 0.019 for spherical grains and 0.012 for nonspherical equidimensional grains, so that the difference in albedo reduction is 0.007 (Fig. 4b). For old nonspherical ( $r=$ $1000 \mu \mathrm{m}$ ) equidimensional snow grains containing the same BC mass, the reduction is about 0.038 for spherical versus 0.056 for nonspherical grains, so that the difference in albedo reduction is 0.018 (Fig. 4b). The difference in albedo reduction increases as $\mathrm{BC}$ mass increases until a
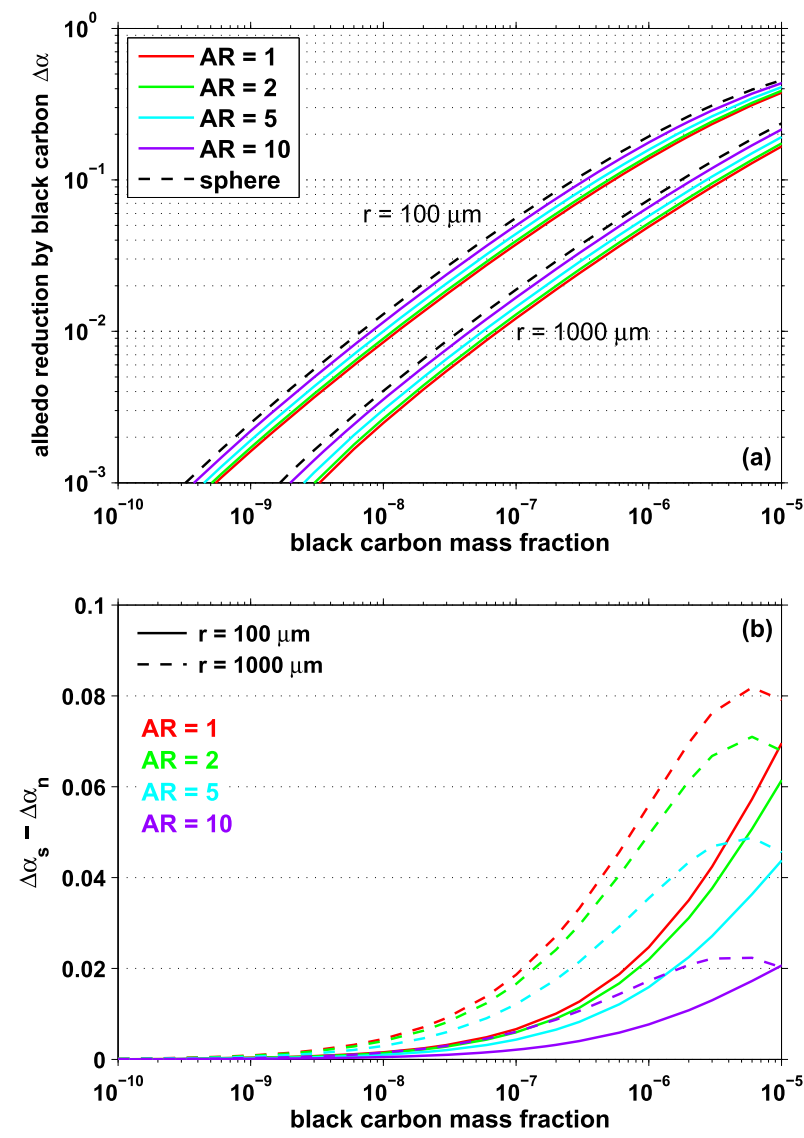

FIG. 4. (a) Reduction of broadband albedo caused by BC $\Delta \alpha$ as a function of BC mass fraction. The value of $\Delta \alpha$ for a snowpack of nonspherical and spherical snow grains is calculated relative to the pure snowpack with nonspherical and spherical snow grains, respectively. (b) The reduction of $\Delta \alpha$ if the snow grains were nonspherical.

maximum is reached, then starts to drop, and becomes insensitive to nonsphericity at large $\mathrm{BC}$ amounts as the albedo of snowpack approaches that of pure BC [Fig. 9a in Dang et al. (2015)]. Therefore, the impact of nonsphericity may be different for different regions. For example, the typical $\mathrm{BC}$ mass fractions observed in snow are on the order of $10^{-8}$ in the Arctic (Doherty et al. 2010) and North America (Doherty et al. 2014) and $10^{-7}$ in China (Wang et al. 2013). In clean regions like the Arctic, and most of North America, the BC concentration is low enough that the albedo reduction caused by $\mathrm{BC}$ is similar regardless of snow grain shapes. In highly polluted regions like China, the albedo reduction caused by $\mathrm{BC}$ is smaller if the snow grain shapes are nonspherical.

The impact of nonsphericity on snow albedo and albedo reduction caused by BC also depends on the SZA (Fig. 5). For snow containing small amounts of $\mathrm{BC}$, if we impose nonsphericity, the albedo enhancement (Fig. 5a) and differences in the albedo reduction caused by BC (Fig. 5b) 

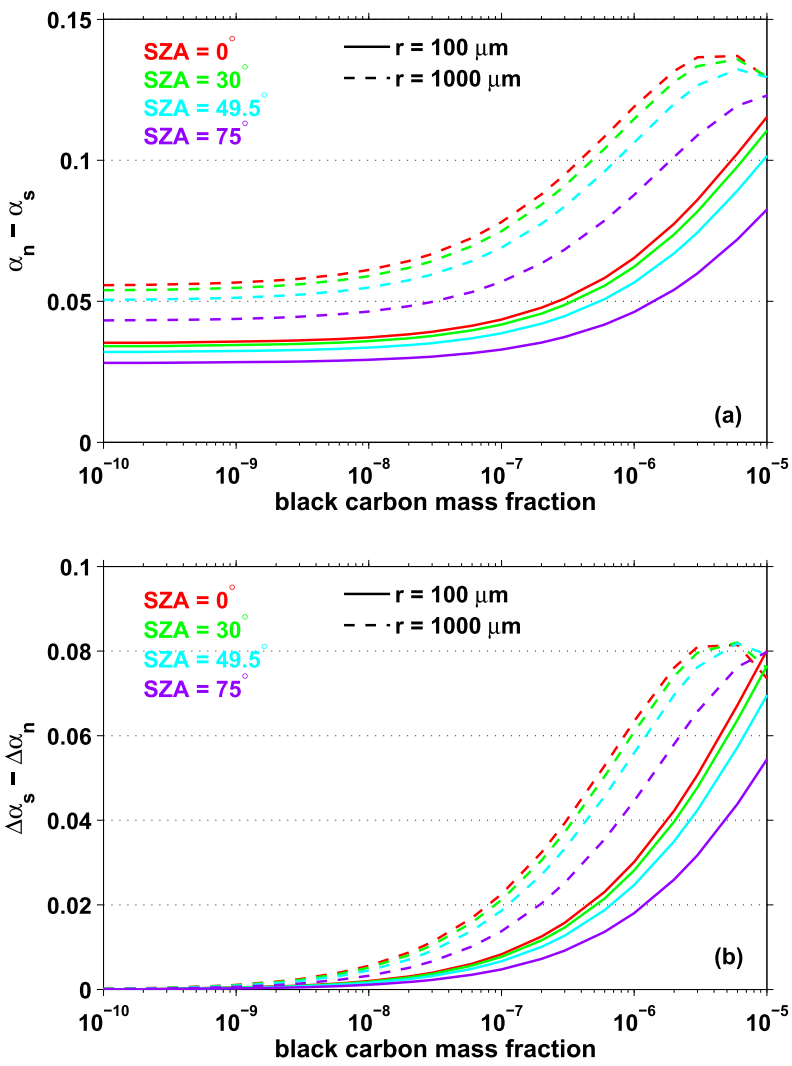

FIG. 5. For different SZA and BC mass fractions, (a) the increase of broadband albedo $\alpha$ and (b) the change in albedo reduction caused by $\mathrm{BC} \Delta \alpha$ if the snow grains were nonspherical. The aspect ratio of the nonspherical grains is 1 .

increase as SZA decreases. This behavior is inverted at $\mathrm{BC}$ concentrations greater than $\sim 10^{-5}$, but such high $\mathrm{BC}$ concentrations are rarely observed (Bond et al. 2013).

\section{2) SHALlOW SNOW}

The broadband albedo of shallow snowpacks is shown in Fig. 6. The topmost curves are the overlap of three curves for new snow with different snow thicknesses (semi-infinite, $1 \mathrm{~m}$, and $0.3 \mathrm{~m}$ ), which illustrate that new snowpack thicker than $0.3 \mathrm{~m}$ is effectively semi-infinite. For old snow $(r=1000 \mu \mathrm{m})$, light penetrates deeper (Wiscombe and Warren 1980), and the albedo shows greater differences for different snow thicknesses. The albedo decreases as the snow thickness decreases, because light has a greater chance to penetrate through the snowpack and be absorbed by the underlying black surface. For snowpacks of the same thickness, the albedo is always higher at $\mathrm{AR}=1$ compared to other nonspherical cases. As we reduce the snow thickness, the albedo reduction is also smaller at $\mathrm{AR}=1$. Thus, for shallow snowpack of any thickness, a higher asymmetry factor yields a lower albedo.

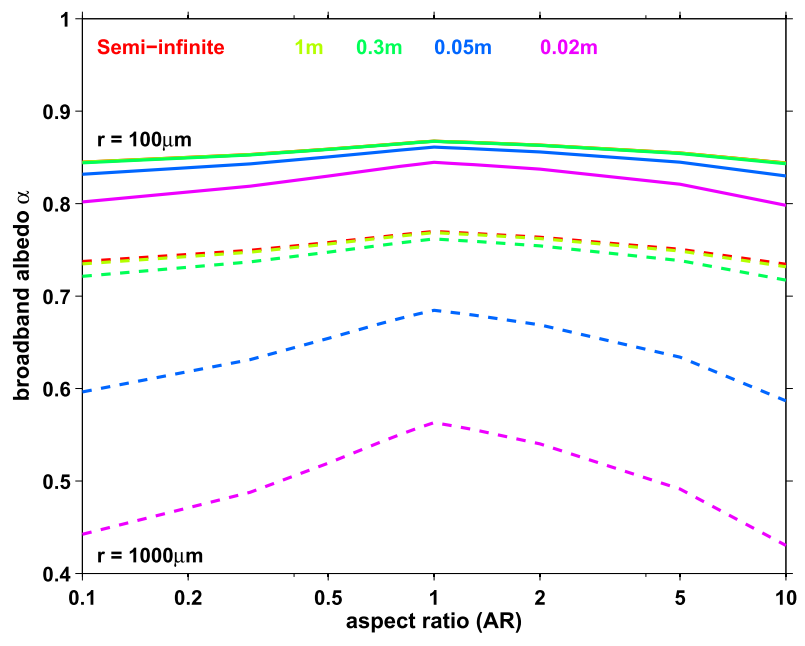

FIG. 6. Broadband albedo $\alpha$ of pure nonspherical snow with different snow thicknesses for snow grain radii of 100 (solid) and $1000 \mu \mathrm{m}$ (dashed), as a function of ice crystal aspect ratio. The underlying surface is black (i.e., underlying surface albedo is zero). Snow density is $300 \mathrm{~kg} \mathrm{~m}^{-3}$.

The albedo of shallow snow containing $\mathrm{BC}$ is shown in Fig. 7. Increasing mass fractions of $\mathrm{BC}$ cause even thin snowpacks to become opaque, until the albedo becomes independent of snow depth.

\section{Comparison to measurements of spectral albedo}

Given the significant effect of nonsphericity on albedo, we need to ask why radiative transfer models for snowpacks of spherical snow grains were able to match field measurements of spectral albedo with high accuracy [Fig. 4 of Grenfell et al. (1994); Fig. 5 of Brandt et al. (2011)]. The answer is that the grain radius $r$ was a free parameter in the modeling. For a semi-infinite pure snowpack, the albedo is insensitive to $g$ at visible and near-ultraviolet wavelengths because ice is essentially nonabsorptive. At wavelengths where ice absorbs, the asymmetry factor $g$ works together with the singlescattering coalbedo $(1-\varpi)$ to determine the albedo, and $(1-\varpi)$ is proportional to $r$ [e.g., Eq. (14) of Warren et al. (2006)]. The grain radius was not measured independently in those field experiments; it was inferred by matching the model to the measurements. For example, as demonstrated in Fig. 8, given a measured snow albedo of 0.59 at wavelength $\lambda=1.3 \mu \mathrm{m}$, modeling pure snow as composed of nonspherical grains with $\mathrm{AR}=1$, a model would yield $r \approx 144$ versus $r \approx 60 \mu \mathrm{m}$ if the grains are modeled as spherical, corresponding to a scaling factor of 2.4. This scaling factor for grain radius would be different from 2.4 if the nonspherical grains have an aspect ratio different from $\mathrm{AR}=1$ (Fig. 1). 

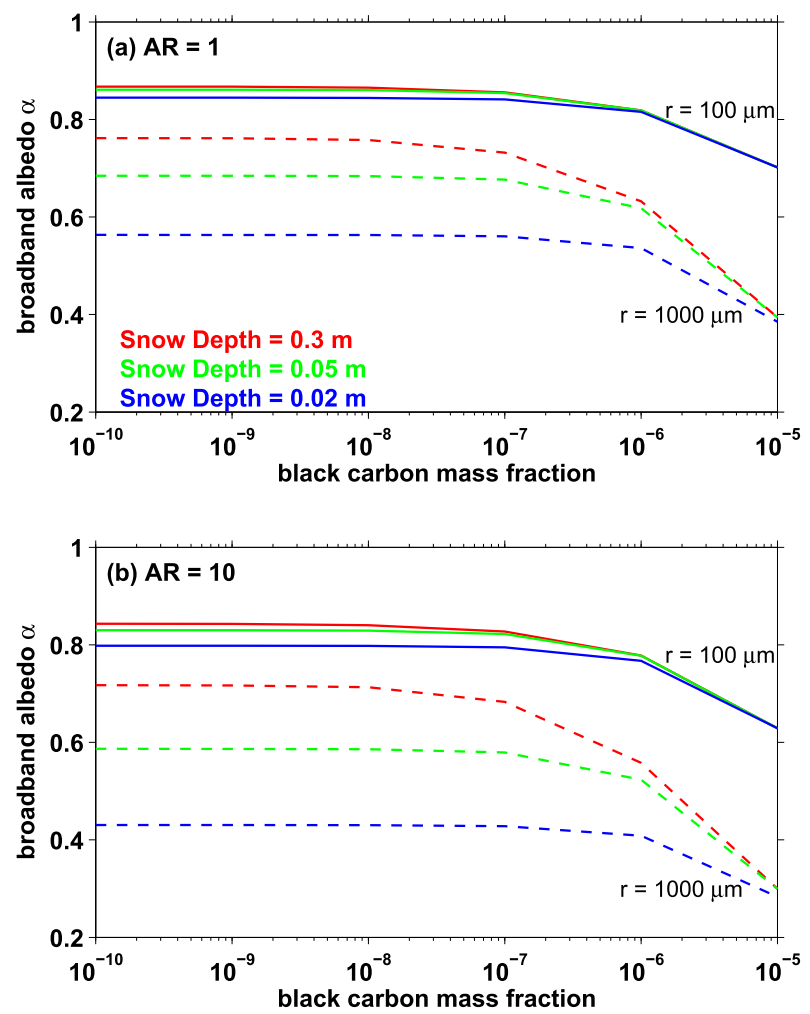

FIG. 7. Broadband albedo $\alpha$ of thin snow containing BC, for snow grain radii 100 and $1000 \mu \mathrm{m}$, as a function of $\mathrm{BC}$ mass fraction. Results are for snow grains with aspect ratio of (a) 1 and (b) 10, assuming the underlying surface is black (i.e., underlying surface albedo is zero). Snow density is $300 \mathrm{~kg} \mathrm{~m}^{-3}$.

For each aspect ratio and snow grain radius, we computed the scaling factor for six cases: thick and thin snowpack (semi-infinite and $2 \mathrm{~cm}$ ), each containing 0 , 100 , or $1000 \mathrm{ng} \mathrm{g}^{-1}$ of $\mathrm{BC}$. The mean and standard deviation of the scaling factor for all six cases are shown in Fig. 9a, for AR =1,2, 5, and 10, as a function of snow grain radius. At any given AR, the scaling factor is almost constant for $r>200 \mu \mathrm{m}$, regardless of snow depth and BC concentration. For $r<200 \mu \mathrm{m}$, the scaling factor increases with grain radius, and the variation with depth and $\mathrm{BC}$ is relatively larger but still negligible.

These results suggest that snow radii inferred from measurements of snow albedo can be scaled to obtain the effective radius of nonspherical grains (example shown in Fig. 8). Conversely, if the specific surface area is measured in a snowpack (e.g., via methane absorption) and converted to effective radius via Eq. (1), this radius would need to be divided by the same scaling factor before computing snow albedo by means of Mie theory and radiative transfer. For example, at any AR, if we use the mean scaling factor for $r=200 \mu \mathrm{m}$ (Fig. 9b) to scale the snow grain radii, and then calculate the snow

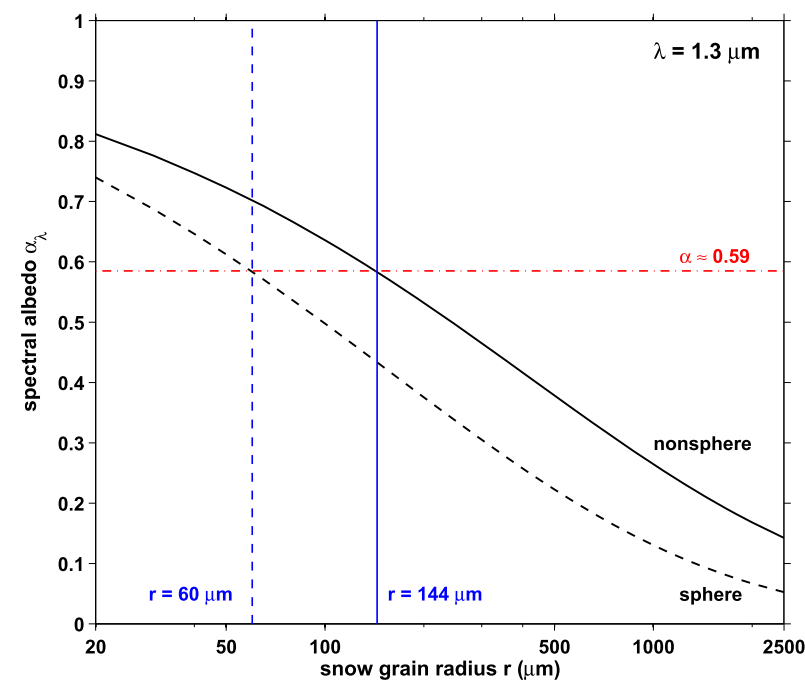

FIG. 8. Spectral albedo $\alpha_{\lambda}(\lambda=1.3 \mu \mathrm{m})$ of semi-infinite snowpack with nonspherical $(\mathrm{AR}=1)$ and spherical snow grains. A measured albedo of 0.59 would cause effective radius to be inferred as $r=60$ or $144 \mu \mathrm{m}$ depending on whether the grains are assumed to be spherical or not.

albedo assuming spherical snow grains, the error in computed albedo is within \pm 0.004 for a semi-infinite snowpack or \pm 0.006 for a 2 -cm snowpack (supplementary Fig. 1), when compared to the albedo of a snowpack composed of nonspherical snow grains with nonscaled radius. If we take into account the dependence of the scaling factor on grain radius (Fig. 9a), this error is further reduced to \pm 0.001 for all six cases (supplementary Fig. 2). Of course, if the radiative transfer calculation has already employed the single-scattering properties of nonspherical ice crystals (e.g., Jin et al. 2008; Ottaviani et al. 2015), such an adjustment to the snow grain radius is unnecessary.

The mean scaling factor (Fig. 9a) is fitted to a polynomial function of snow grain radius for each of nine aspect ratios (supplementary Fig. 3). The functions and coefficients are given in the supplementary Table 1. Again, we remind the reader that the use and interpretation of a scaling factor for snow grain radius depends on the research focus. The scaling procedure has been tested only for albedo, not other radiative quantities. For example, it would not work to compute bidirectional reflectance, which has a much greater dependence on grain shape (Xie et al. 2006).

\section{Discussion and conclusions}

In this work, we have calculated the albedo of snow for various snow grain sizes, snow depths, BC mass fractions, and for a range of aspect ratios of snow grains. 

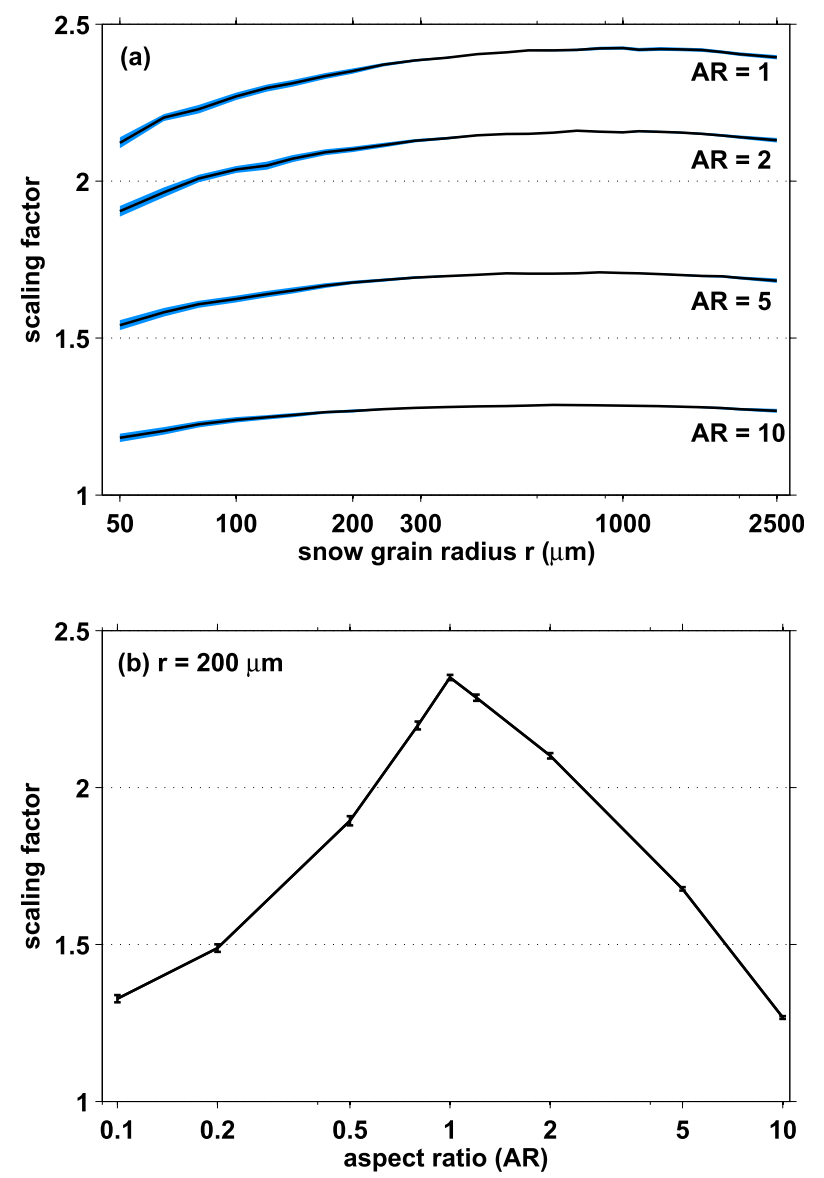

FIG. 9. Scaling factors for different grain radii and aspect ratios, so that the spectral albedo computed by a model of spheres can match the spectrum of a snowpack of nonspherical grains. (a) Mean scaling factor of six cases for each AR (varying snow depth and BC content); blue shading shows plus or minus one standard deviation. (b) Mean and standard deviation of scaling factor for snow grains with radius $200 \mu \mathrm{m}$.

The asymmetry factor of snow grains is sensitive to the grain shape. At $\lambda=0.5 \mu \mathrm{m}, g=0.89$ for spherical snow grains; while for nonspherical snow grains, it is a function of the particle aspect ratio, with the lowest value $g \approx 0.74$ at $\mathrm{AR}=1$. Though the sphere and equidimensional nonsphere both have $\mathrm{AR}=1$, their asymmetry factors are very different. For all aspect ratios between 0.1 and 10 , the asymmetry factor of a nonspherical ice particle is always smaller than or equal to that of a sphere. Compared with the albedo of spherical grains, a snowpack of equidimensional nonspheres has higher albedo for all snow depths and BC mass fractions. For pure deep snow, the increases of snow albedo are 0.032 and 0.050 for new snow and old snow, respectively. For snow containing $100 \mathrm{ng} \mathrm{g}^{-1} \mathrm{BC}$, the increase of snow albedo is 0.039 for new snow and 0.069 for old snow. A smaller asymmetry factor results in a smaller albedo reduction caused by $\mathrm{BC} ; 100 \mathrm{ng} \mathrm{g}^{-1}$ of $\mathrm{BC}$ can reduce the albedo of spherical new snow by 0.019 , but only by 0.012 in the case of nonspherical snow. For larger grain sizes this difference is larger. The computed effect of BC may therefore be overestimated when using spherical grains in radiative transfer models, unless the grain size in the model is chosen to match the measurements of albedo.

In terms of climatological impacts, an increase of snow albedo due to nonsphericity will reduce the energy absorbed by snowpack. For a typical daily average solar irradiance of $400 \mathrm{~W} \mathrm{~m}^{-2}$ in the Arctic late spring and early summer, an enhancement of broadband albedo of 0.01 will reduce the energy by $4 \mathrm{~W} \mathrm{~m}^{-2}$ locally. This forcing will be different for different latitudes and times. Imposing an albedo reduction (e.g., due to BC) for snow and ice by 0.015 in the Arctic and 0.030 in the midlatitude Northern Hemisphere caused a hemisphericaverage climate forcing of $0.3 \mathrm{~W} \mathrm{~m}^{-2}$ (Hansen and Nazarenko 2004). These amounts of albedo reduction would be smaller if we consider the nonsphericity of snow grains, unless these models chose the grain size to match the albedo measurements.

Radiative transfer models for snowpacks of spherical snow grains were able to match field measurements of spectral albedo to high accuracy by varying the snow grain radius in the model. In the same situation, a snowpack of nonspherical grains would imply smaller specific surface area (larger effective radius) by a factor of up to 2.4.

As snow ages, the snow grains become more rounded and are often connected more or less to each other. The definition of a snow "grain" is therefore ambiguous, but the specific surface area (and therefore the corresponding "effective radius") is not ambiguous, because the specific surface area is just the area-to-mass ratio in bulk snow and has a 1:1 relation to effective radius [Eq. (1)]. In climate models, it is hard if not impossible to predict the natural snow crystal shape for different snow age and meteorological conditions, let alone to assign different asymmetry factors to different snowpacks based on snow grain shape. To bridge this gap, more measurements of phase function of natural/artificial snowpacks are needed. Such measurements (e.g., Räisänen et al. 2015; Ottaviani et al. 2015) are useful to evaluate the asymmetry factor used in current radiative transfer models and also for their implications to the snow grain shape.

Acknowledgments. This research was supported by NSF Grant AGS-11-18460 and NASA Grant NNX13AN49G. We thank the three reviewers for their helpful suggestions and comments. 


\section{REFERENCES}

Aoki, T., T. Aoki, M. Fukabori, A. Hachikubo, Y. Tachibana, and F. Nishio, 2000: Effects of snow physical parameters on spectral albedo and bidirectional reflectance of snow surface. J. Geophys. Res., 105, 10219-10 236, doi:10.1029/1999JD901122.

— , K. Kuchiki, M. Niwano, Y. Kodama, M. Hosaka, and T. Tanaka, 2011: Physically based snow albedo model for calculating broadband albedos and the solar heating profile in snowpack for general circulation models. J. Geophys. Res., 116, D11114, doi:10.1029/2010JD015507.

Baum, B. A., P. Yang, A. J. Heymsfield, C. G. Schmitt, Y. Xie, A. Bansemer, Y. Hu, and Z. Zhang, 2011: Improvements in shortwave bulk scattering and absorption models for the remote sensing of ice clouds. J. Appl. Meteor. Climatol., 50, 1037-1056, doi:10.1175/2010JAMC2608.1.

Bond, T. C., and Coauthors, 2013: Bounding the role of black carbon in the climate system: A scientific assessment. J. Geophys. Res. Atmos., 118, 5380-5552, doi:10.1002/jgrd.50171.

Brandt, R. E., S. G. Warren, and A. D. Clarke, 2011: A controlled snowmaking experiment testing the relation between black carbon content and reduction of snow albedo. J. Geophys. Res., 116, D08109, doi:10.1029/2010JD015330.

Carmagnola, C. M., and Coauthors, 2013: Snow spectral albedo at Summit, Greenland: Measurements and numerical simulations based on physical and chemical properties of the snowpack. Cryosphere, 7, 1139-1160, doi:10.5194/tc-7-1139-2013.

Clarke, A. D., K. J. Noone, J. Heintzenberg, S. G. Warren, and D. S. Covert, 1967: Aerosol light absorption measurement techniques: Analysis and intercomparisons. Atmos. Environ., 21, 1455-1465, doi:10.1016/0004-6981(67)90093-5.

Dadic, R., P. C. Mullen, M. Schneebeli, R. E. Brandt, and S. G. Warren, 2013: Effects of bubbles, cracks, and volcanic tephra on the spectral albedo of bare ice near the Transantarctic Mountains: Implications for sea glaciers on Snowball Earth. J. Geophys. Res. Earth Surf., 118, 1658-1676, doi:10.1002/ jgrf.20098.

Dang, C., R. E. Brandt, and S. G. Warren, 2015: Parameterizations for narrowband and broadband albedo of pure snow and snow containing mineral dust and black carbon. J. Geophys. Res. Atmos., 120, 5446-5468, doi:10.1002/2014JD022646.

Doherty, S. J., S. G. Warren, T. C. Grenfell, A. D. Clarke, and R. Brandt, 2010: Light-absorbing impurities in Arctic snow. Atmos. Chem. Phys., 10, 11 647-11 680, doi:10.5194/ acp-10-11647-2010.

, C. Dang, D. A. Hegg, R. Zhang, and S. G. Warren, 2014: Black carbon and other light-absorbing particles in snow of central North America. J. Geophys. Res. Atmos., 119, 12 807-12 831, doi:10.1002/2014JD022350.

Flanner, M. G., and C. S. Zender, 2006: Linking snowpack microphysics and albedo evolution. J. Geophys. Res., 111, D12208, doi:10.1029/2005JD006834.

— — - J. T. Randerson, and P. J. Rasch, 2007: Present day climate forcing and response from black carbon in snow. J. Geophys. Res., 112, D11202, doi:10.1029/2006JD008003.

— $\longrightarrow$ X. Liu, C. Zhou, J. E. Penner, and C. Jiao, 2012: Enhanced solar energy absorption by internally-mixed black carbon in snow grains. Atmos. Chem. Phys., 12, 4699-4721, doi:10.5194/ acp-12-4699-2012.

Francis, P. N., A. Jones, R. W. Saunders, K. P. Shine, A. Slingo, and Z. Sun, 1994: An observational and theoretical study of the radiative properties of cirrus: Some results from ICE'89. Quart. J. Roy. Meteor. Soc., 120, 809-848, doi:10.1002/qj.49712051804.
Fu, Q., 1996: An accurate parameterization of the solar radiative properties of cirrus clouds for climate models. $\mathrm{J}$. Climate, 9, 2058-2082, doi:10.1175/1520-0442(1996)009<2058: AAPOTS $>2.0 . \mathrm{CO} ; 2$.

— 2007: A new parameterization of an asymmetry factor of cirrus clouds for climate models. J. Atmos. Sci., 64, 4144-4154, doi:10.1175/2007JAS2289.1.

__, P. Yang, and W. B. Sun, 1998: An accurate parameterization of the infrared radiative properties of cirrus clouds for climate models. J. Climate, 11, 2223-2237, doi:10.1175/ 1520-0442(1998)011<2223:AAPOTI >2.0.CO;2.

_ W. B. Sun, and P. Yang, 1999: On modeling of scattering and absorption by nonspherical cirrus ice particles in thermal infrared wavelengths. J. Atmos. Sci., 56, 2937-2947, doi:10.1175/ 1520-0469(1999)056<2937:MOSAAB > 2.0.CO;2.

Gardner, A. S., and M. J. Sharp, 2010: A review of snow and ice albedo and the development of a new physically based broadband albedo parameterization. J. Geophys. Res., 115, F01009, doi:10.1029/2009JF001444.

Garrett, T. J., P. V. Hobbs, and H. Gerber, 2001: Shortwave, singlescattering properties of arctic ice clouds. J. Geophys. Res., 106, 15 155-15 172, doi:10.1029/2000JD900195.

Grannas, A. M., and Coauthors, 2007: An overview of snow photochemistry: Evidence, mechanisms and impacts. Atmos. Chem. Phys., 7, 4329-4373, doi:10.5194/acp-7-4329-2007.

Grenfell, T. C., and S. G. Warren, 1999: Representation of a nonspherical ice particle by a collection of independent spheres for scattering and absorption of radiation. J. Geophys. Res., 104, 31 697-31 709, doi:10.1029/1999JD900496.

— and D. K. Perovich, 2008: Incident spectral irradiance in the Arctic Basin during the summer and fall. J. Geophys. Res., 113, D12117, doi:10.1029/2007JD009418.

_ , S. G. Warren, and P. C. Mullen, 1994: Reflection of solar radiation by the Antarctic snow surface at ultraviolet, visible, and near-infrared wavelengths. J. Geophys. Res., 99, 18669 18 684, doi:10.1029/94JD01484.

— S. P. Neshyba, and S. G. Warren, 2005: Representation of a nonspherical ice particle by a collection of independent spheres for scattering and absorption of radiation: 3 . Hollow columns and plates. J. Geophys. Res., 110, D17203, doi:10.1029/2005JD005811.

Hansen, J., and L. Nazarenko, 2004: Soot climate forcing via snow and ice albedos. Proc. Natl. Acad. Sci. USA, 101, 423-428, doi:10.1073/pnas.2237157100.

Holz, R. E., and Coauthors, 2016: Resolving ice cloud optical thickness biases between CALIOP and MODIS using infrared retrievals. Atmos. Chem. Phys., 16, 5075-5090, doi:10.5194/ acp-16-5075-2016.

Jin, Z., T. P. Charlock, P. Yang, Y. Xie, and W. Miller, 2008: Snow optical properties for different particle shapes with application to snow grain size retrieval and MODIS/CERES radiance comparison over Antarctica. Remote Sens. Environ., 112, 3563-3581, doi:10.1016/j.rse.2008.04.011.

Joseph, J. H., W. J. Wiscombe, and J. A. Weinman, 1976: The deltaEddington approximation for radiative flux transfer. J. Atmos. Sci., 33, 2452-2459, doi:10.1175/1520-0469(1976)033<2452: TDEAFR $>2.0 . \mathrm{CO} ; 2$.

Key, J. R., P. Yang, B. A. Baum, and S. L. Nasiri, 2002: Parameterization of shortwave ice cloud optical properties for various particle habits. J. Geophys. Res., 107, doi:10.1029/ 2001JD000742.

LaChapelle, E. R., 1969: Field Guide to Snow Crystals. University of Washington Press, 112 pp. 
Lawrence, D. M., and Coauthors, 2011: Parameterization improvements and functional and structural advances in version 4 of the Community Land Model. J. Adv. Model. Earth Syst., 3, M03001, doi:10.1029/2011MS000045.

Libois, Q., G. Picard, J. L. France, L. Arnaud, M. Dumont, C. M. Carmagnola, and M. D. King, 2013: Influence of grain shape on light penetration in snow. Cryosphere, 7, 1803-1818, doi:10.5194/tc-7-1803-2013.

,-- M. Dumont, L. Arnaud, C. Sergent, E. Pougatch, M. Sudul, and D. Vial, 2014: Experimental determination of the absorption enhancement parameter of snow. J. Glacial., 60, 714-724, doi:10.3189/2014JoG14J015.

Liou, K. N., Y. Takano, C. He, P. Yang, R. L. Leung, Y. Gu, and W. L. Lee, 2014: Stochastic parameterization for light absorption by internally mixed $\mathrm{BC} /$ dust in snow grains for application to climate models. J. Geophys. Res. Atmos., 119, 7616-7632, doi:10.1002/2014JD021665.

Macke, A., J. Mueller, and E. Raschke, 1996: Single scattering properties of atmospheric ice crystals. J. Atmos. Sci., 53, 2813-2825, doi:10.1175/1520-0469(1996)053<2813:SSPOAI $>2.0 . C O ; 2$

Marshall, S. E., and S. G. Warren, 1987: Parameterization of snow albedo for climate models. Large Scale Effects of Seasonal Snow Cover, B. E. Goodison, R. G. Barry, and J. Dozier, Eds., IAHS Publ. 166, 43-50. [Available online at http://iahs.info/ uploads/dms/iahs_166_0043.pdf.]

Mullen, P. C., and S. G. Warren, 1988: Theory of the optical properties of lake ice. J. Geophys. Res., 93, 8403-8414, doi:10.1029/ JD093iD07p08403.

Neshyba, S. P., T. C. Grenfell, and S. G. Warren, 2003: Representation of a nonspherical ice particle by a collection of independent spheres for scattering and absorption of radiation: 2. Hexagonal columns and plates. J. Geophys. Res., 108, 4448 , doi:10.1029/2002JD003302.

Ottaviani, M., B. van Diedenhoven, and B. Cairns, 2015: Photopolarimetric retrievals of snow properties. Cryosphere, 9, 1933-1942, doi:10.5194/tc-9-1933-2015.

Painter, T. H., A. P. Barrett, C. C. Landry, J. C. Neff, M. P. Cassidy, C. R. Lawrence, K. E. McBride, and G. L. Farmer, 2007: Impact of disturbed desert soils on duration of mountain snow cover. Geophys. Res. Lett., 34, L12502, doi:10.1029/2007GL030284.

— , S. M. Skiles, J. S. Deems, A. C. Bryant, and C. C. Landry, 2012: Dust radiative forcing in snow of the Upper Colorado River Basin: 1. A 6 year record of energy balance, radiation, and dust concentrations. Water Resour. Res., 48, W07521, doi:10.1029/2012WR011985.

Qian, Y., W. I. Gustafson Jr., L. R. Leung, and S. J. Ghan, 2009: Effects of soot-induced snow albedo change on snowpack and hydrological cycle in western United States based on Weather Research and Forecasting chemistry and regional climate simulations. J. Geophys. Res., 114, D03108, doi:10.1029/ 2008JD011575.

Räisänen, P., A. Kokhanovsky, G. Guyot, O. Jourdan, and T. Nousiainen, 2015: Parameterization of single-scattering properties of snow. Cryosphere, 9, 1277-1301, doi:10.5194/ tc-9-1277-2015.

Stephens, G. L., S.-C. Tsay, P. W. Stackhouse Jr., and P. J. Flatau, 1990: The relevance of the microphysical and radiative properties of cirrus clouds to climatic feedback. J. Atmos. Sci., 47, 1742-1753, doi:10.1175/1520-0469(1990)047<1742: TROTMA $>2.0 . \mathrm{CO} ; 2$.
Sun, W. B., Q. Fu, and Z. Z. Chen, 1999: FDTD solution of light scattering by dielectric using PML ABC. Appl. Opt., 38, 3141-3151, doi:10.1364/AO.38.003141.

van Diedenhoven, B., B. Cairns, I. V. Geogdzhayev, A. M. Fridlind, A. S. Ackerman, P. Yang, and B. A. Baum, 2012: Remote sensing of ice crystal asymmetry parameter using multi-directional polarization measurements-Part I: Methodology and evaluation with simulated measurements. Atmos. Meas. Tech., 5, 2361-2374, doi:10.5194/amt-5-2361-2012.

—, A. S. Ackerman, B. Cairns, and A. M. Fridlind, 2014: A flexible parameterization for shortwave optical properties of ice crystals. J. Atmos. Sci., 71, 1763-1782, doi:10.1175/ JAS-D-13-0205.1.

Wang, X., S. J. Doherty, and J. Huang, 2013: Black carbon and other light-absorbing impurities in snow across Northern China. J. Geophys. Res. Atmos., 118, 1471-1492, doi:10.1029/ 2012JD018291.

Warren, S. G., 1982: Optical properties of snow. Rev. Geophys. Space Phys., 20, 67-89, doi:10.1029/RG020i001p00067.

_ , and W. J. Wiscombe, 1980: A model for the spectral albedo of snow. II: Snow containing atmospheric aerosols. J. Atmos. Sci., 37, 2734-2745, doi:10.1175/1520-0469(1980)037<2734: AMFTSA $>2.0 . \mathrm{CO} ; 2$.

, and R. E. Brandt, 2008: Optical constants of ice from the ultraviolet to the microwave: A revised compilation. J. Geophys. Res., 113, D14220, doi:10.1029/2007JD009744.

, ——, and T. C. Grenfell, 2006: Visible and near-ultraviolet absorption spectrum of ice from transmission of solar radiation into snow. Appl. Opt., 45, 5320-5334, doi:10.1364/ AO.45.005320.

Wiscombe, W. J., 1980: Improved Mie scattering algorithms. Appl. Opt., 19, 1505-1509, doi:10.1364/AO.19.001505.

_ snow. I: Pure snow. J. Atmos. Sci., 37, 2712-2733, doi:10.1175/ 1520-0469(1980)037<2712:AMFTSA > 2.0.CO;2.

Xie, Y., P. Yang, B. C. Gao, G. W. Kattawar, and M. I. Mishchenko, 2006: Effect of ice crystal shape and effective size on snow bidirectional reflectance. J. Quant. Spectrosc. Radiat. Transfer, 100, 457-469, doi:10.1016/j.jqsrt.2005.11.056

Yang, P., and K. N. Liou, 1995: Light scattering by hexagonal ice crystals: Comparison of finite-difference time domain and geometric optics models. J. Opt. Soc. Amer., 12A, 162-176, doi:10.1364/JOSAA.12.000162.

$\longrightarrow$, and — 1996: Finite-difference time domain method for light scattering by small ice crystals in three-dimensional space. J. Opt. Soc. Amer., 13A, 2072-2085, doi:10.1364/ JOSAA.13.002072.

, and Q. Fu, 2009: Dependence of ice crystal optical properties on particle aspect ratio. J. Quant. Spectrosc. Radiat. Transfer, 110, 1604-1614, doi:10.1016/j.jqsrt.2009.03.004.

_ K. N. Liou, K. Wyser, and D. Mitchell, 2000: Parameterization of the scattering and absorption properties of individual ice crystals. J. Geophys. Res., 105, 4699-4718, doi:10.1029/ 1999JD900755.

Zatko, M. C., T. C. Grenfell, B. Alexander, S. J. Doherty, J. L. Thomas, and X. Yang, 2013: The influence of snow grain size and impurities on the vertical profiles of actinic flux and associated NOx emissions on the Antarctic and Greenland ice sheets. Atmos. Chem. Phys., 13, 3547-3567, doi:10.5194/ acp-13-3547-2013. 